\title{
Striatal topographical organization: Bridging the gap between molecules, connectivity and behavior
}

\author{
Gianpaolo Antonio Basile, ${ }^{1 *}$ Salvatore Bertino, ${ }^{1 *}$ Alessia Bramanti, ${ }^{2}$ Rosella Ciurleo,,${ }^{3}$ Giuseppe Pio Anastasi, ${ }^{1}$ \\ Demetrio Milardi, ${ }^{1}$ Alberto Cacciola ${ }^{1}$
}

${ }^{1}$ Brain Mapping Lab, Department of Biomedical, Dental Sciences and Morphological and Functional Images, University of Messina; 'Department of Medicine, Surgery and Dentistry "Medical School of Salerno", University of Salerno; ${ }^{3}$ IRCCS Centro Neurolesi “Bonino Pulejo”, Messina, Italy

\section{*These authors equally contributed to the present work}

The striatum represents the major hub of the basal ganglia, receiving projections from the entire cerebral cortex and it is assumed to play a key role in a wide array of complex behavioral tasks. Despite being extensively investigated during the last decades, the topographical organization of the striatum is not well understood yet. Ongoing efforts in neuroscience are focused on analyzing striatal anatomy at different spatial scales, to understand how structure relates to function and how derangements of this organization are involved in various neuropsychiatric diseases. While being subdivided at the macroscale level into dorsal and ventral divisions, at a mesoscale level the striatum represents an anatomical continuum sharing the same cellular makeup. At the same time, it is now increasingly ascertained that different striatal compartments show subtle histochemical differences, and their neurons exhibit peculiar patterns of gene expression, supporting functional diversity across the whole basal ganglia circuitry. Such diversity is further supported by afferent connections which are heterogenous both anatomically, as they originate from distributed cortical areas and subcortical structures, and biochemically, as they involve a variety of neurotransmitters. Specifically, the cortico-striatal projection system is topographically organized delineating a functional organization which is maintained throughout the basal ganglia, subserving motor, cognitive and affective behavioral functions. While such functional heterogeneity has been firstly conceptualized as a tripartite organization, with sharply defined limbic, associative and sensorimotor territories within the striatum, it has been proposed that such territories are more likely to fade into one another, delineating a gradient-like organization along medio-lateral and ventro-dorsal axes. However, the molecular and cellular underpinnings of such organization are less understood, and their relations to behavior remains an open question, especially in humans. In this review we aimed at summarizing the available knowledge on striatal organization, especially focusing on how it links structure to function and its alterations in neuropsychiatric diseases. We examined studies conducted on different species, covering a wide array of different methodologies: from tract-tracing and immunohistochemistry to neuroimaging and transcriptomic experiments, aimed at bridging the gap between macroscopic and molecular levels.

Key words: Basal ganglia; cortex; fMRI; gradients; tractography.

Correspondence: Alberto Cacciola, Brain Mapping Lab, Department of Biomedical, Dental Sciences and Morphological and Functional Images, University of Messina, Italy. Tel. +39.090.2217143.

E-mail: alberto.cacciola0@gmail.com

Contributions: $\mathrm{GAB}, \mathrm{SB}$, conceptualization, original draft writing; $\mathrm{AB}$, manuscript review and editing, data curation; RC, visualization; GPA, manuscript review and editing; DM, supervision, manuscript review and editing; AC, conceptualization, manuscript review and editing, supervision.

Conflict of interest: The authors declare that they have no competing interests, and all authors confirm accuracy. 


\section{Introduction}

The striatum acts in close conjunction with the cerebral cortex and different subcortical structures to transform activity in the cortex into various cognitive, affective and motor functions. The striatal regions receiving inputs from neocortical areas are the caudate, putamen and core of the nucleus accumbens, which mainly consist of medium-sized spiny GABAergic projection neurons (MSNs). ${ }^{1-3}$. Anatomical tract-tracing studies in non-human primates, as well as in vivo studies using resting-state functional MRI and diffusion-based tractography in the human brain, revealed a series of parallel cortico-striato-thalamo-cortical circuits. Such connections from distinct cortical areas are likely to be topographically organized in segregated, identifiable, yet integrated territories in the whole basal ganglia system..$^{4-1}$. However, despite recent advances in brain mapping techniques, cortico-basal ganglia neural circuits are some of the least understood pathways, especially in the human brain. According to the classical perspective, the cerebral cortex and subcortex are organized into discrete, segregated areas tightly working together. Notwithstanding, there is emerging evidence of a continuous transition in connectivity patterns along a primary organizational axis. Indeed, it has been demonstrated that the projections from cortex are topographically organized in a ventral-to-dorsal and a medial-to-lateral gradient across the striatum. ${ }^{16-18}$ This gradient-like topographical organization has probably a key functional relevance in determining how the striatum interacts with cortex and subcortical structures, subserving complex behaviors.

Whether such topographical organization of connectivity is reflected at the cellular and subcellular level is still a major unsolved issue. While striatal cells show high heterogeneity in terms of genetic, molecular and receptor expression, ${ }^{19-21}$ if and how specific molecular expression patterns are related to the functional organization of striatum into parallel circuits is still matter of debate. A detailed characterization of the molecular underpinnings of striatal organization is fundamental to understand the generation of complex behavior, as well as for the pathophysiology and treatment of many brain disorders, which symptoms are likely to stem from selective dysfunctions of distinct striatal subterritories. ${ }^{22}$

The present review aims at providing a comprehensive overview on the striatal topographical organization and its relationship with specific attributes of motor and non-motor behavior bridging the gap between macroscopic and molecular levels of analysis. First, we will describe the anatomical and molecular topography of the striatum, highlighting the organization of subcortical and cortical striatal connectivity and its molecular correlates. We will then link structural and functional striatal topography to complex behavior and explore the relationship between molecular patterns of expression and morphological and functional aspects of the striatum. Finally, we will briefly discuss the pathophysiological relevance of striatal topography in different neurologic and psychiatric disorders.

\section{Anatomical and molecular topography of the striatum}

\section{Functional anatomy of the striatum}

In primates, the striatum is traditionally subdivided into a dorsal striatum (DS), which includes caudate and putamen, and a ventral striatum (VS), which includes the nucleus accumbens (NAcc) and other forebrain structures such as the olfactory tubercle and the rostrolateral substantia innominata. ${ }^{4,23}$ Albeit having some relevant differences, these structures are usually considered as a continuum as they share the same organizational principles. In general, striatal cells (both belonging to DS or VS) can be subdivided into projection cells and interneurons. Projection cells are mostly GABAergic MSNs; ${ }^{1-3}$ these neurons project to subcortical structures, such as the pallidal complex (external pallidum, GPe; internal pallidum, $\mathrm{GPi}$; ventral pallidum, VeP) and substantia nigra (SN). ${ }^{24-27}$ Interneurons are the less represented cell type ${ }^{2,28}$ and are generally subdivided into cholinergic interneurons $(\mathrm{ChIN}),{ }^{29}$ and GABAergic interneurons, which are further distinguished by different patterns of expression of enzymes and neuropeptides. ${ }^{30}$ Both MSNs and interneurons receive afferents from three distinct sources: the cerebral cortex, ${ }^{31,32}$ the thalamus ${ }^{33,34}$ and the brainstem. ${ }^{35,36}$. A fourth source of afferent connections, amygdala, is specific for VS neurons as it involves only to limited extent DS neurons. ${ }^{37,38}$. Cortico-striatal and thalamo-striatal connections are glutamatergic and are distinguished by different transport molecules expression and functional activity; ${ }^{34,39}$ brainstem projections are mostly dopaminergic and they originate from the ventral midbrain (substantia nigra pars compacta, $\mathrm{SNc}$; ventral tegmental area, VTA) ${ }^{40,41}$ despite serotoninergic projections from the dorsal raphe have been also described. ${ }^{36,42}$

Histochemical studies conducted on rats revealed that DS neurons can be subdivided into striatal patches (also called striosomes) which are identified by positivity to mu-opiates receptors, ${ }^{43}$ and a matrix compartment, originally defined by positivity to somatostatin $^{44}$ and calbindin ${ }^{19}$ as well as many other molecular markers. ${ }^{21}$ Such histochemical organization has been described also in cats, ferrets, ${ }^{45}$ monkeys ${ }^{46}$ and humans,${ }^{47}$ suggesting that it is phylogenetically conserved. In addition, a recent study on transgenic mice demonstrated the existence of a third population of striatal projection neurons (so-called "exopatch" neurons) which reside in the matrix compartment but show neurochemical and electrophysiological features of striatal patch neurons. ${ }^{48}$ On the other hand, the VS represents an exception as patch and matrix regions cannot be easily identified; nevertheless, it shows some similarities as it is constituted by a dorsolateral shell region, that is positive to muopiates receptor and negative to calbindin, and a ventromedial region which is rich in calbindin. ${ }^{49}$ In addition, some specific cell types in VS are arranged in cell islands (islands of Calleja) which are not present in the DS; these islands, which have been described in several mammalians including non-human and human primates, ${ }^{50}$ have a peculiar core of granule cells ${ }^{51}$ and show distinctive molecular features, such as expression of reproductive neurohormones ${ }^{52}$ and of the anti-apoptotic molecule bcl-2. ${ }^{53}$

\section{Principles of striatal morphofunctional organization}

The best characterized model of organization of the striatum is based on the efferent subcortical connectivity, i.e., the organization of projections from the striatum to other basal ganglia structures. According to this model, striatal projection neurons engage two distinct, subcortical connectivity pathways: the "direct" and "indirect" pathways. This "dual stream" model is phylogenetically conserved across vertebrates such as rats, monkeys and humans. ${ }^{54}$

In the "direct" pathway, striatal projection neurons target the $\mathrm{GPi}$ and the substantia nigra pars reticulata $(\mathrm{SNr})$, which, in turn, send inhibitory projections to the thalamus, which projects again to the striatum and the cerebral cortex. In the "indirect" pathway, striatal projection neurons target the GPe, which in turn projects to the subthalamic nucleus (STN). The STN, which is a mainly glutamatergic region, targets the GPi and $\mathrm{SNr}^{14,5}$. Traditionally, the net effect of the activity of such pathways on the cerebral cortex and thalamus has been modeled in terms of recurrent inhibition or disinhibition; ${ }^{56}$ nonetheless, these notions represent an oversimplification, of which more recent models of basal ganglia physiology 
tend to be more aware. ${ }^{57,58}$ Studies carried out on both rats and primates showed that the "dual stream" model of striatal organization is strongly correlated with histochemical features of striatal neurons and their molecular co-expression patterns: striatal projection neurons involved in the direct pathway co-express dopamine receptor D1, substance-P and dynorphin, while striatal projection neurons involved in the indirect pathway co-express dopamine receptor D2 and enkephalin..$^{59,60}$ More recently, clustering of transcriptomic data from mouse striatum revealed specific subsets of genes which expression differentiates between D1-expressing (Drdla, Tacl, Isl1) and D2-expressing MSNs (Drd2, Adora2a, Penk, Gpr6 and Gp52) ${ }^{61}$ (Figure 1).

A second level of organization of striatal neurons emerges from afferent cortical connectivity; a large body of research conducted mostly on non-human primates showed that the whole striatum indeed receives a massive, topographically organized innervation from the whole cerebral cortex, and in particular from the frontal lobe. ${ }^{32}$ This peculiar organization of cortico-striatal projections has been originally described in term of parallel, segregated circuits originating from specific sites of the frontal cortex and targeting specific striatal territories. ${ }^{62}$ In particular, the topographical organization of fronto-striatal projections follows a ventro-dorsal and medio-lateral arrangement which is specular to that of the cortical mantle, i.e. ventral and medial regions of the striatum receive projections from ventral and medial regions of the prefrontal cortex (cingulum, orbitofrontal cortex, ventromedial prefrontal cortex), while dorsal and lateral regions of the striatum receive projections from dorsal and lateral regions of the frontal cortex, as well as the primary motor regions. ${ }^{17,63-67}$

The segregation between cortical projection territories, however, is not strict. The presence of parallel and segregated basal ganglia circuits, each one processing a peculiar type of input, has been challenged by the description of functional overlap, allowing the integration of multimodal information. Indeed, variable degrees of overlap and interdigitation have been demonstrated both between striatal projection territories of frontal regions, and between frontal projection territories and projection territories from other brain regions, such as parietal, extrastriate occipital and temporal cortex..$^{31,32,68-70}$ A general rule of thumb, recently reformulated from critical revision of anatomical data, is that regions which show strong cortico-cortical connectivity generally show overlapping striatal territories. ${ }^{71}$ Taken together, these results have been often conceptualized in terms of a tripartite model of cortico-striatal organization, where cortical projections identify three distinct territories which fade into one another in the rostrocaudal and dorsoventral axes: a limbic-ventral territory centered on the nucleus accumbens, an associative-dorsal territory centered on the caudate, and a sensorimotor-caudal territory centered on the putamen. ${ }^{72,73}$ The tripartite organization consisting of limbic, associative and sensorimotor territories has been demonstrated also in the dorsal striatum of rats, where a clear distinction between caudate and putamen lacks. ${ }^{74}$ However, the molecular correlates of this functional and anatomical subdivision are less known.

\section{Molecular gradients of the striatum may reflect the parallel-circuits organization}

Several studies have been conducted on both human and nonhuman primates to understand the molecular underpinnings of striatal functional organization. Since dopaminergic projections from the dorsal tier of SNc and ventral tegmental area terminate predominantly on ventral territories of the striatum, while projections from the ventral tier of SNc terminate mainly on the dorsolateral striatum, ${ }^{35,40}$ the striatal dopamine system has been proposed as the first candidate to reflect such spatial segregation. In line with this hypothesis, in non-human primates the levels of dopamine transporter (DAT) have been found to be higher in the motor striatal territories compared to the ventral striatum ${ }^{75-77}$ and this different pattern of expression may explain the different dynamics of extracellular dopamine transients observed among different functional territories. ${ }^{78}$ Accordingly, dopamine concentration and homovanillic

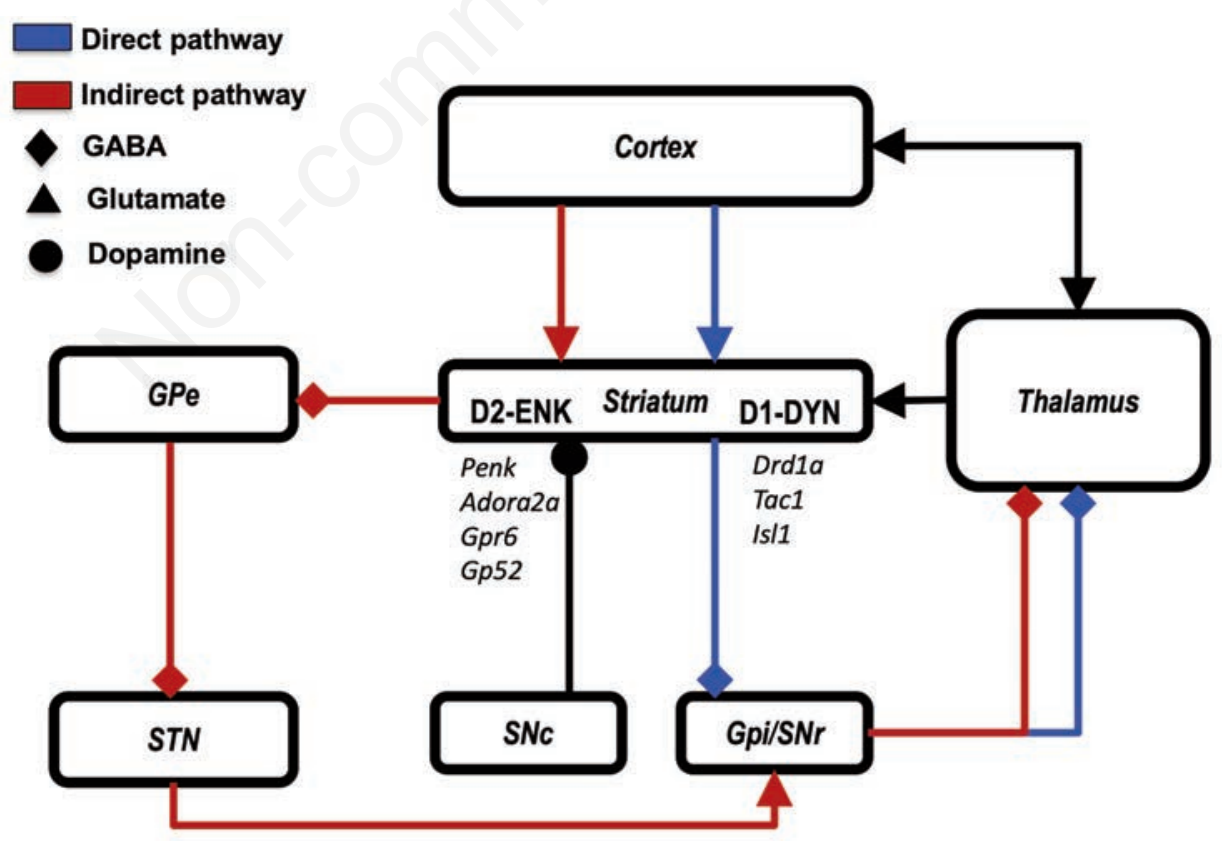

Figure 1. Subcortical connectivity of the striatum. Widespread cortical projections reach the striatal neurons which are engaged in direct (blue) and indirect (red) pathways before reaching the thalamus which in turn projects back to the cortex. The former engages neurons which project to GPi and SNr, the latter involves neurons and detours through two synaptic stations, namely the GPe and the STN, prior to reach the GPi/SNr complex. Neurons involved in the direct pathway co-express dopamine receptor D1, substance $\mathrm{P}$ and dynorphin while those engaged in the indirect pathway co-express dopamine receptor D2 and enkephalin. These subsets of neurons demonstrated characteristic patterns of gene expression. 
acid-to-dopamine ratio (HVA/DA) sampled from human specimens showed a similar spatial arrangement, suggesting higher dopamine availability and turnover in the dorsolateral compared to the ventromedial striatum. ${ }^{79}$ Concerning dopamine receptors, in primates, dopamine receptor D1 expression has a rostrocaudal declining gradient in the putamen but not in the caudate, while dopamine receptor D2 expression increases rostrocaudally both in caudate and in putamen, being maximal in the dorsolateral putamen; ${ }^{80}$ however, this latter finding is controversial as other investigations found a decreasing rostrocaudal gradient. ${ }^{81}$ D3 dopamine receptor is concentrated in the ventral striatum, in particular nucleus accumbens, but it does not follow a rostrocaudal expression gradient. ${ }^{80,82-84}$ Other neurotransmitters and receptors, such as serotonin and acetylcholine and their markers (serotonine transporter, SERT; choline-acetyltransferase, ChAT), show a compartmental organization within the primate striatum: for example, ChATexpressing interneurons are likely to be more represented in the associative compartment of the striatum, followed by motor and limbic territories; ${ }^{85}$ SERT-marked neurons show instead a spatial pattern which is less easily related to cortical topography, being higher in rostrodorsal and caudoventral striatum and particularly expressed in the head of caudate nucleus. ${ }^{86}$

Recently, the expanding fields of genomics and transcriptomics have provided additional insight about molecular differences between functional compartments of the striatum. Microarray analysis in mice suggested that genes for prodynorfin (Pdyn), AMPA-glutamate receptor 1 subunit (Grial) and other genes related to GABA-ergic signaling (GABA-transporter Slc6a1; GABA $_{\mathrm{A}}$ receptor subunit Gabra5) may be expressed preferentially in the nucleus accumbens, while genes for dopamine receptor D2 (Drd2), cathecolol-O-metyltransferase (Comt) and other molecules related to glutamatergic and GABA-ergic transmission may be preferentially expressed in the dorsal striatum. ${ }^{87}$ Accordingly, a recent analysis based on RNA sequencing in mice revealed significant heterogeneity in the co-expression patterns of D2 receptor-expressing neurons: among genes preferentially expressed on the dorsal striatum, some showed a preferential expression in medial versus lateral striatum or showed a patch-matrix segregated expression, while among genes that show a biased expression in nucleus accumbens, some were specifically localized to core, ventral, medial or lateral shell. ${ }^{88}$ Furthermore, along with cell type-specific expression markers, some molecules which show topographically organized expression both in the mouse and marmoset striatum have been identified; these molecules, such as Crym or Gpr155, show a clear medio-lateral distribution and, interestingly, are not expressed in specific subtypes of striatal projection neurons, but rather may represent a shared molecular code found in all the striatal projection neurons localized in a certain functional domain. ${ }^{89}$ Although limited to non-

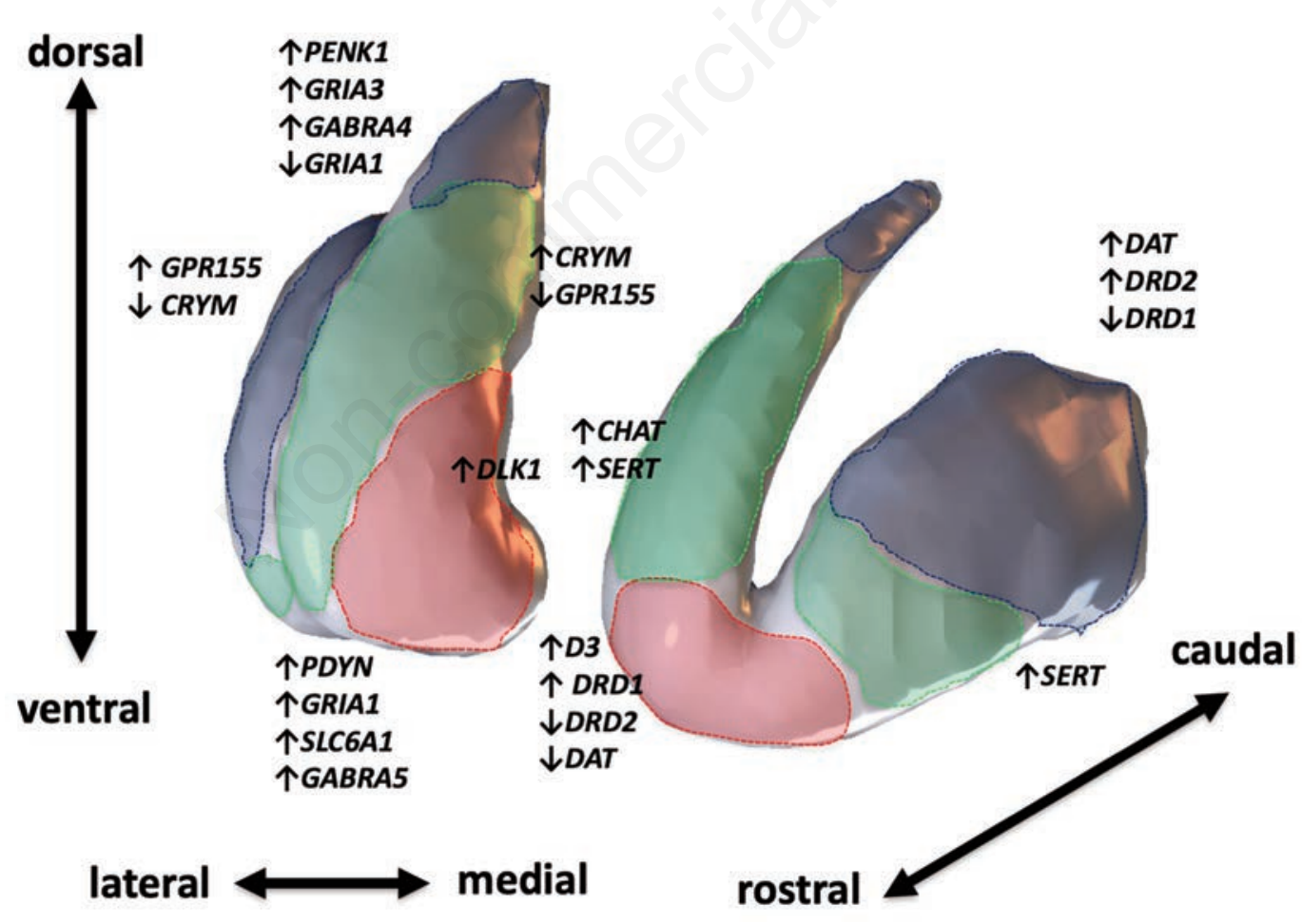

Figure 2. Molecular diversity of striatal subterritories. Some examples of molecular markers which show differential expression across different territories of the striatum. Dotted borders encompass putative functional striatal territories defined by cortical connections; red, limbic-ventral; green, associative-dorsal; blue, sensorimotor-caudal. Boundaries of limbic, associative and sensorimotor territories have been drawn manually for schematic visualization purpose considering the evidence of available studies in literature. Among molecular markers, some show a graded expression across the rostral-caudal (e.g., DAT, dopamine receptors) or medial-lateral axis (e.g, CRYM; GPR155; DLK1); other discriminate between dorsal and ventral striatum (PDYN; PENK1; GABRA4; GABRA5) and other are increased in specific subterritories which are less clearly related to cortical topography (e.g., CHAT, SERT). Additionally, it has been suggested that D2-expressing projection neurons (not showed) show topographically specific expression patterns. ${ }^{88}$ 
human species, these recent works strongly suggest that the spatial and functional organization of cortico-striatal connectivity may be encoded at deeper, cell-specific molecular and transcriptional levels (Figure 2).

\section{Structural and functional striatal connectivity reflect complex behavior}

\section{Visualizing the striatal organization in vivo: the contri- bution of neuroimaging}

Despite much of the ground truth on topographic organization of the cortico-striatal system comes from studies conducted on primates, the advances of MRI-based techniques allowed to map such connections also in-vivo in humans by using structural and functional connectivity. ${ }^{90}$ While the former can be investigated with diffusion tractography, which allows the reconstruction of white matter bundles by modeling diffusion signal at voxel level, ${ }^{91-96}$ functional connectivity is commonly derived by exploiting the spontaneous fluctuations of blood-oxygenated level depended (BOLD) signal during resting-state fMRI. ${ }^{97}$

Previous diffusion tractography studies primarily investigates striatal connectivity in a target-based fashion, i.e. by extracting and quantifying streamlines connecting striatal regions to target regions, thus obtaining measures of connectivity "strength" between striatum and other brain regions. As an example, Lehéricy and colleagues employed diffusion tensor imaging and tractography to reconstruct connections between the frontal lobe and striatum, ${ }^{98,99}$ showing that the posterior putamen was connected to primary sensorimotor cortices as well as to SMA while the anterior putamen was mainly connected to pre-SMA, caudate nucleus was mainly connected to dorsal and ventral prefrontal cortices, and ventral striatum was mainly connected to medial orbitofrontal cortex. ${ }^{99}$ Similar results were reported by a study conducted on six subjects using tensor-based probabilistic tractography which investigated fronto-striatal connectivity, depicting also subcortical connections with cerebellum for both caudate and putamen, as previously demonstrated in non-human primates studies. ${ }^{100,101}$ Despite the results of such studies are in line with the findings obtained in non-human primates, hinting for a similar tripartite organization of striatum also in humans, connections with parietal, temporal and occipital cortices were poorly represented. Such finding may be due to the restricted sample size or to limitations of the diffusion tensor model. ${ }^{102}$ A more recent work investigating striatal connectivity using a connectomic approach based on high-order diffusion modeling and probabilistic tractography found that the caudate head and body showed prominent connections with prefrontal areas such as the superior frontal gyrus, rostral part of the middle frontal gyrus, inferior frontal gyrus and with lateral orbito-frontal cortex. On the other hand, the putamen presented more pronounced connectivity with parietal areas linked with sensorimotor functions and with supramarginal, lingual gyri and insula. ${ }^{103}$

Along with quantifying the connectivity profiles of striatal nuclei as a whole, tractography has been also used to reconstruct the spatial organization of striatal connections by mapping streamlines from the whole cortical mantle on the striatal volume: such method has confirmed that, in line with animal studies, connectivity between cortex and striatum is organized in a continuous fashion along the medio-lateral and rostro-caudal axes of the striatum. ${ }^{104}$

Information extracted from diffusion tractography can be also used to classify and parcellate the striatum into subregions which show distinctive connectivity features. A seminal work conducted by Draganski and colleagues ${ }^{105}$ studied segregation and integration of basal ganglia circuits studying both cortical and subcortical connectivity of caudate, putamen, globus pallidus and thalamus using multi-tensor diffusion modeling and probabilistic tractography. Such study provided connectivity-based parcellation of these structures as well as the identification of putative relay zones (i.e. voxels connected with all the structures included in circuits defined by tract-tracing or neurophysiologic studies conducted on non-human primates). The authors showed that connections with frontal areas were topographically organized within the striatum, forming a gradient of partially overlapping territories such that limbic-related areas were mainly connected to ventral striatum, associative areas to central striatum whilst sensorimotor areas were connected to dorsolateral portions of caudate and putamen. ${ }^{105}$ Another interesting finding, in line with animal literature, is that the topographical organization of the striatum is mirrored across the whole connectional system of the basal ganglia, including the GPe, GPi, STN and thalamus; e.g., the peculiar topographical organization obtained by mapping cortical connectivity on the striatum is maintained when mapping striatal connectivity to the GP. ${ }^{106}$ This parallel-circuits organization of the striatum, as revealed by structural connectivity-based parcellation, seems to be substantially preserved when using other imaging modalities, such as resting-state fMRI. By evaluating functional connectivity of six distinct seed points placed throughout the striatum, similar connectivity profiles have been indeed observed using resting-state fMRI in a sample of healthy subjects. ${ }^{107}$ Specifically, NAcc and ventral caudate showed dissociable functional connectivity patterns, being the former connected with the medial orbitofrontal cortex, parahippocampal gyrus and cingulate cortex, whilst the latter with the lateral orbitofrontal cortex. The dorsal caudate exhibited more pronounced connectivity with dorsolateral prefrontal cortex, inferior frontal cortex, inferior parietal lobule and middle frontal gyrus. Finally, dorsal putamen clusters showed functional connectivity with primary and higher-order motor cortices while the ventral putamen showed connectivity with anterior cingulate cortex. ${ }^{107} \mathrm{~A}$ ultra-high-field MRI study conducted on a few subjects has extensively investigated subcortical basal ganglia connections combining diffusion tractography and rs-fMRI; briefly, once structural connectivity-derived clusters were obtained, their functional connectivity profiles were also investigated, revealing a substantial overlap with the structural connectivity profiles. ${ }^{108}$

A connectivity-based parcellation of the basal ganglia can also be obtained by using computational methods based on clustering of functional connectivity data. Such approaches have been successfully employed over the last decade to identify spatially independent, large scale co-activation networks, as well as to obtain functional, unsupervised striatal parcellations based on the contribution of striatal territories to such networks. ${ }^{109}$ Choi and colleagues identified distinct striatal sub-regions according to their functional connectivity with these distributed cortical networks, thus obtaining a complete functional map of the striatum both at coarse and fine-grained levels. These findings suggest that the subdivision of striatum in limbic, associative and sensorimotor territories may oversimplify the complex functional interplay between the striatum and large scale networks of the cerebral cortex, that may be instead better captured by more sophisticated techniques to model cortico-striatal topography. ${ }^{110}$

In this regard, recent advances in functional neuroimaging have put forward the opportunity of modelling spatially continuous gradients of connectivity, rather than discrete parcels, by using manifold learning algorithms. ${ }^{111,112}$

A recent study employed such technique to investigate striatal connectivity gradients (or connectopies) using resting-state fMRI data; a first medio-lateral gradient of connectivity distinguished caudate from putamen and a second, ventro-dorsal gradient, 
matched the cortical connectivity profiles of ventral and dorsal striatal subdivisions, when projected to the cerebral cortex. ${ }^{11}$.

Increasingly sophisticated computational models can be applied to functional connectivity data to provide additional insights on the complex organization of the striatal system. Gradientography, a recently developed fMRI analogue of diffusion MRI tractography, enables the quantification of subcortical connectivity gradients and a statistically principled formalism to guide boundary delineation. By using this approach, it was possible to reconcile hard parcellations with gradient-based models as the former can be obtained from the latter, with biologically meaningful boundaries corresponding to sharp variation in the gradients. In particular parcellations were obtained from gradients at different levels of granularity: in the case of striatum, the first scale of parcellation successfully separated caudate, putamen and NAcc, whilst the second seemingly identified head, body and tail of caudate nuclei and shell and core sub-regions of NAcc. ${ }^{114}$

Taken together, neuroimaging studies confirm and further expand the existing knowledge from non-human primates on striatal structure and function. Converging experimental results from different imaging modalities are currently shaping the field, shedding new light on how striatum interacts with several brain networks to harmonize motor and non-motor behavior.

\section{Behavioral characterization of striatal territories}

Along with visualizing cortico-striatal topographical organization in vivo, the advances of neuroimaging techniques have also allowed to investigate differential contribution of these subregions in distinct behavioral paradigms.

Historically considered as mainly involved in motor functions, the widespread cortical connectivity of the striatum and its peculiar topographic organization hint for a more complex behavioral role, spanning from emotion-related to cognitive and motor behavior. For this reason, a plethora of task-based fMRI studies have been conducted in order to disentangle the complex behavioral role of striatum. The results of such line of research have been nicely summarized by a recent meta-analytic study. ${ }^{115}$ In particular, areas of the ventral striatum (nucleus accumbens, ventral caudate and putamen) were significantly activated during encoding of stimulus value thus suggesting a role for the ventral striatum in driving reward-based responses. ${ }^{116,117}$

While the anterior caudate nucleus showed significant activation when specific actions led to rewards, suggesting its specific role in incentive behavior or action value encoding, ${ }^{118}$ the posterior caudate nucleus is likely to be mainly involved in executive functions such as cognitive control and task-shifting. ${ }^{119}$ The putamen has been traditionally associated with motor functions such as motor preparation and execution ${ }^{120}$ co-activating with premotor and supplementary motor cortices. ${ }^{107}$ However, the posterior putamen exhibited significant co-activation with higher order somatosensory cortices where painful stimuli were delivered to hands or feet, suggesting its role in decoding also affective qualities of sensory stimuli. ${ }^{121}$ Moreover, strong coactivation of anterior putamen with the inferior frontal gyrus has been found during nonmotor tasks, such as social and language related functions. ${ }^{122}$

In addition, a recent work using a manifold learning approach to model the functional connectivity gradients of the human striatum revealed that variations in the ventro-dorsal connectivity gradient were significantly related to delay discounting, relational processing and psychological wellbeing for the left hemisphere and social cognition, sustained attention and personality for the right hemisphere. ${ }^{113}$

More recently, task-based behavioral characterization has been used in conjunction with data-driven, multi-modal parcellation of striatum on a large sample of both healthy subjects and patients revealing that clusters obtained with different neuroimaging modalities showed a behavioral characterization that is coherent with existing literature. ${ }^{123}$

Taken together, these results suggest that striatal topographically specific contribution to behavioral tasks may be investigated in vivo using different neuroimaging techniques. Even if differences in striatal parcellation may arise due to imaging modalities and pipelines employed, behavioral characterization seems to be univocal regardless of the methodological issues suggesting that cortico-striatal connectivity is multi-faceted but subserves the same array of behavioral functions (Figure 3). Along with ascertaining that striatum contributes to a wide array of complex behavioral functions, and that distinct striatal territories are involved in specifical behavioral tasks, functional neuroimaging has also clarified how different striatal subregions co-operate to generate complex responses to the environment. Lesion studies carried out on rodents suggested that the striatum is involved in different kinds of instrumental behavior. Specifically, the dorsomedial striatum has been linked to goal-directed behavior, ${ }^{124,125}$ whilst the dorsolateral striatum is likely to play a role in habit-based behavior. ${ }^{126,127}$ Interestingly, similar behavioral results were obtained when lesions were located in distinct prefrontal areas projecting to striatum in a topographically organized manner. ${ }^{128-130}$ Such findings have been mostly paralleled in humans, engaging subjects in taskbased fMRI experiments designed to identify regions implied in goal-directed and habit-formation behavior. On one hand, medial prefrontal cortex, together with anterior caudate nucleus were involved in action-outcome contingency, which is crucial for goaldirected behavior. ${ }^{131-133}$ On the other hand, subjects which underwent extensive action-outcome contingency training did not retain outcome sensitivity; such behavioral outcome corresponded to increased activity in posterior putamen supporting the notion that habit formation take place in the dorsolateral striatum. ${ }^{134,135}$ These works enforce the hypothesis, put forward in animal models, that the transition from goal-directed to habitual behavior may be paralleled by a shift towards prominent activity of dorsomedial-versus-dorsolateral striatum. ${ }^{136}$

\section{From molecules to connectivity: promises and per- spectives}

\section{Bringing together imaging and molecular investigation}

As discussed above, the results of recent neuroimaging and behavioral works strongly reinforce the concept of functional specialization within the human striatum, while suggesting that partially overlapping striatal subterritories may work in concert to mediate complex behavior. A puzzling question in neuroscientific research concerns the cellular and molecular mechanisms underlying such segregation and integration features.

Traditionally, positron emission tomography (PET) has been widely employed to explore in vivo functional and molecular features of the striatum, with specific focus on the striatal dopaminergic system. ${ }^{137-13}$. However, PET has been rarely used to investigate molecular and biochemical diversity across striatal subregions, mostly due to its low spatial resolution. ${ }^{140}$ Nevertheless, a seminal work by Tziortzi and colleagues, which combined tractography with [(11)C]propylhexahidronaphtooxazinol- (PHNO) and $[(11) C]$ raclopride-PET, demonstrated that D-amphetamine administration induced the highest dopamine release in the limbic followed by the sensory, motor, and executive areas in healthy humans, ${ }^{141}$ thus confirming that different striatal circuits may show distinct features of response to dopamine stimulation.

The recent availability of large-scale, anatomically compre- 
hensive human gene expression atlases, ${ }^{142-144}$ coupled with the recent progresses in computational connectomics and transcriptomics, ${ }^{145}$ have offered new tools to bridge the gap between in vivo human neuroimaging and molecular biology.

Despite a close link between transcription levels of peculiar clusters of genes and functional connectivity networks throughout the human brain has been demonstrated, ${ }^{146-148}$ to date only a few works have examined the molecular correlates of striatal structural and functional connectivity. Parkes and colleagues employed structural connectivity to parcellate the striatum into ventral/limbic, dorsal/associative and caudal/sensorimotor domains and implemented a machine-learning based approach to find out transcriptional profiles accurately predicting their striatal subregion of origin. Gene enrichment analysis revealed that a first component, which was discriminative between ventral and dorsal subregions and correlated to the ventrodorsal axis, showed enrichment for biological processes such as dopamine receptor signaling (genes coding for dopamine receptors D1, D2 and D3) and response to amphetamines, catecholamines and monoamines; two additional components, that accurately classified the caudal subregion of striatum and were correlated to the mediolateral axis, showed enrichment for glutamate secretion molecules. ${ }^{149}$ These results are in line with animal literature suggesting differential expression of genes for dopamine and glutamate neurotransmission along striatal territories, ${ }^{83,87}$ and confirm that structural connectivity-based parcellation can be implemented to reconstruct biologically meaningful subterritories of the human striatum.

Additional information may come by comparing these results with those obtained by employing functional connectivity, i.e. by classifying striatal subregions according to their specific involvement in cortico-subcortical widespread functional networks. ${ }^{110} \mathrm{~A}$ recent study combining such approach with large-scale human transcriptomics revealed identifiable, discriminative transcription patterns for functional, network-based subdivision for the striatum: for instance, the limbic subregion of striatum was identified by high enrichment of genes for somatostatin (SST) and related recep- tors (SSTR1, SSTR2), while genes for parvalbumin (PVALB) were enriched in the sensorimotor subregion of striatum. ${ }^{150}$ These results are of great interest since both SST and PVALB are differentially expressed markers of striatal GABA-ergic interneurons, ${ }^{30,151}$ thus suggesting that this specific cell class, albeit being relatively few-represented among striatal cells, ${ }^{2}$ would play a specific role in mediating coordinated functional activity of corticostriatal networks. In addition, another interesting finding of this study is that striatal gene co-expression patterns mirror aspects of cortical gene co-expression across functional networks; i.e. there is correlation between the striatal and cortical expression pattern of certain genes expressed in the same functional network. ${ }^{150}$ In line with this hypothesis, following investigations have revealed a strongly anti-correlated SST- $v s$-PVALB expression gradient in the human and non-human primate cerebral cortex, with SST being more expressed in limbic cortices and PVALB being more expressed in associative and sensorimotor cortices (Figure 4). ${ }^{152}$

Hence, taken together these results may allow for a tighter link between human functional task-based neuroimaging and animal molecular/behavioral studies. Indeed, striatal PVALB-expressing GABA-ergic inter-neurons have been implicated in associative learning and sensorimotor integration ${ }^{153,154}$ while striatal SSTexpressing interneurons might play a role in motivated, goaldirected learning ${ }^{155}$ and their suppression has been showed to increase the expression of DAT in the ventral striatum and decrease the motivational effects of cocaine assumption while increasing cocaine-induced hyperlocomotion in mice. ${ }^{156}$

\section{Pathophysiological relevance of striatal topography}

In summary, the currently expanding fields of studies bringing together human neuroimaging to transcriptomics may add novel insight on striatal functional organization and may guide towards a better comprehension of molecular mechanisms underlying complex behavior. Understanding the molecular correlates of corticostriatal circuitry is of uttermost importance as striatal subregions may be differentially affected in neurodevelopmental, psychiatric

\section{Structural}

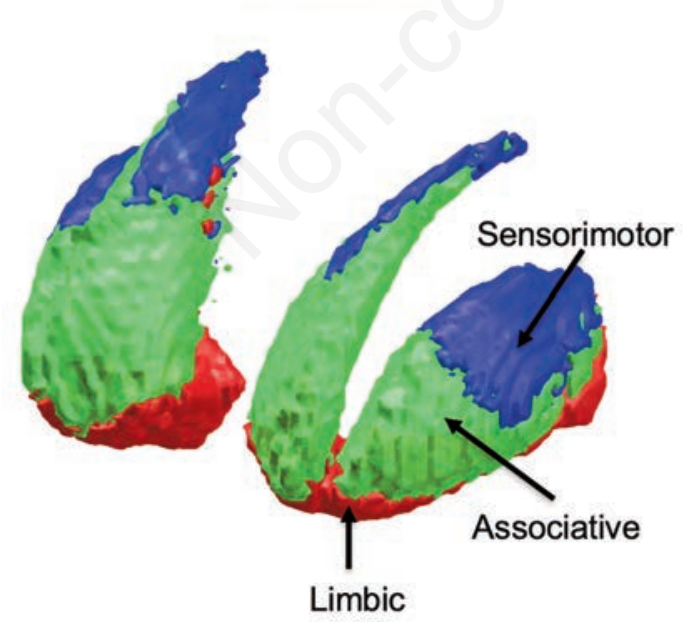

\section{Functional}

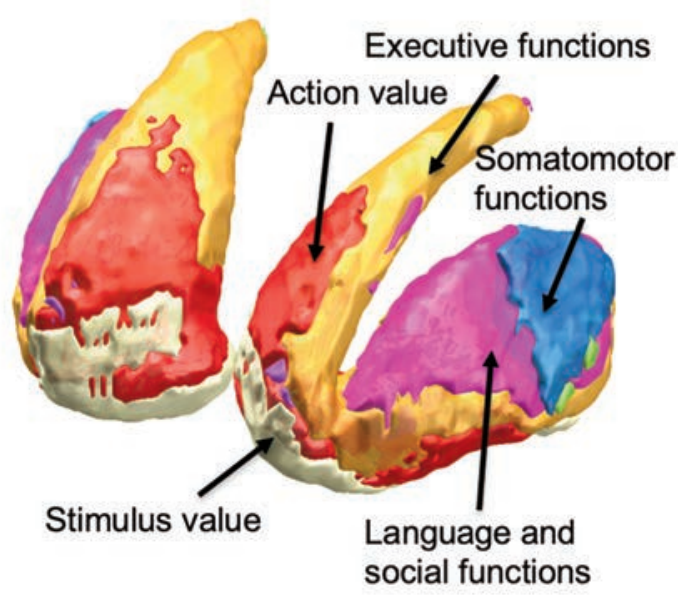

Figure 3. Striatal topography according to structural and functional connectivity. Right: Striatal functional territories obtained by diffusion tractography ${ }^{141}$ are arranged along the ventro-dorsal and rostro-caudal axes. The ventral striatum (red) is mainly connected to ventromedial prefrontal cortices, the antero-dorsal territory (green) or the central striatum has stronger connectivity with prefrontal areas related to cognition, the postero-dorsal territory (blue) or the posterior striatum is mainly connected to sensorimotor areas. Left: Striatal territories defined using resting-state functional MRI, classified according corresponding cortical networks as follows: limbic (cream), default mode (red), frontoparietal (orange), somatomotor (light blue), dorsal attention (green), ventral attention (purple) and visual (violet). ${ }^{110}$ Behavioral labeling follows task-based activation of selected striatal territories. ${ }^{15}$ 


\section{Structural}

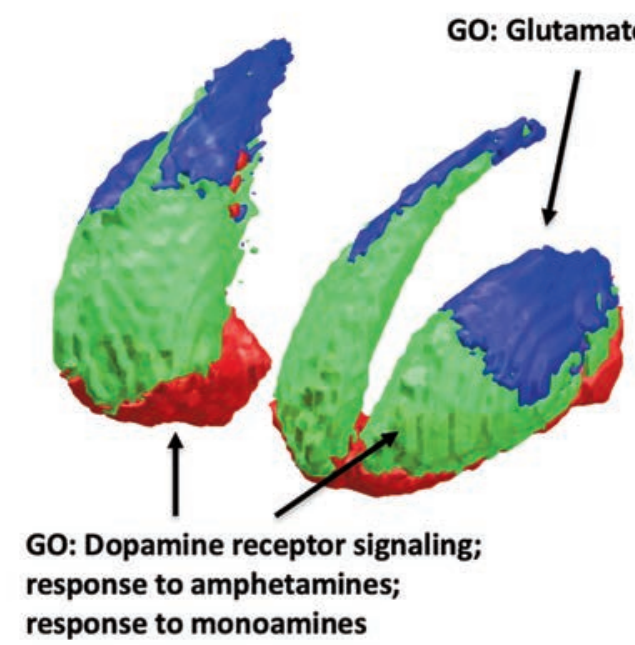

\section{Functional}

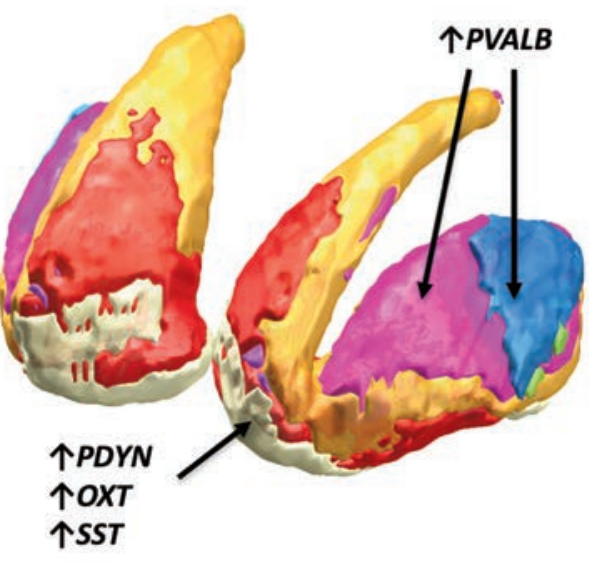

Figure 4. Molecular correlates of striatal structural and functional organization. Left: Gene expression correlates of structural connectivity based-parcellation. Genes showing enrichment for dopamine receptor signaling process (dopamine receptors D1, D2, D3, endocannabinoid system) are correlated to the dorsoventral axis and identify dorsal and ventral striatum, while genes showing enrichment for glutamate secretion identify the caudal striatum; GO, gene ontology. Right: Gene expression correlates of functional connectivity based-parcellation: Genes for prodynorfin (PDYN), oxitocyn (OXT), somatostatin (SST) and others (not mentioned) are preferentially expressed in the limbic network-related striatum, while genes for parvalbumin (PVALB) are preferentially expressed in the ventral attention network-related and somatomotor striatum.

and movement disorders including autism spectrum disorders, ${ }^{157}$ addiction, ${ }^{158}$ schizophrenia, ${ }^{159,160}$ obsessive-compulsive disorder (OCD), ${ }^{161}$ Parkinson's disease (PD) and Huntington's disease. ${ }^{162}$ In line with this perspective, it is not surprising that some of the genes which expression was related to different structural or functional territories of striatum were found to be associated with high risk of autism, neurodevelopmental syndromes, PD and schizophrenia. ${ }^{150,152,163}$

The tripartite model of striatal organization has boosted the knowledge on the role of striatal dysfunction in different motor, cognitive and behavioral disorders. ${ }^{22}$ Extending to neuropsychiatric symptoms the well-known model of hyper- and hypokinetic movement disorders, which are thought to derive respectively from increased and decreased activity in the motor striatum, ${ }^{55}$ it has been suggested that decreased activity in the limbic striatum may lead to depressed mood and anhedonia, ${ }^{164}$ while increased activity may lead to impulsive-compulsive behavior such as those observed in addiction, OCD and eating disorders. ${ }^{165,166}$ Increased activity in the cognitive-associative striatal territories, on the other hand, is likely to be involved in inattention and executive deficits in attention deficit/hyperactivity disorder. ${ }^{167}$

In addition, moving beyond the traditional view that postulates different striatal territories as being selectively and exclusively involved in distinct neuropsychiatric diseases (e.g. dorsal putamen in PD or nucleus accumbens in schizophrenia and addiction) ${ }^{17,37}$, recent evidence suggests that different parts of the cortico-striatal circuitry may be involved in different symptoms and manifestations of the same disease. For example, in patients suffering from $\mathrm{PD}$, it has been suggested that dorso-lateral striatum may be also involved in dual-tasking performance deficits ${ }^{168}$ and in cognitive/executive impairment, ${ }^{169}$ while the ventral striatum may be related to depressive symptoms which are frequently associated to $\mathrm{PD} ;{ }^{170}$ in schizophrenic patients, recent evidence highlights that topographically specific involvement of different striatal circuits may contribute to different symptom manifestations; ${ }^{171,172}$ finally, in obsessive-compulsive disorder, different subregions of the cortico-striatal circuitry are thought to mediate different symptom dimensions. ${ }^{173-175}$ In this framework, a better understanding of the molecular patterns of expression underlying the topographical organization of cortico-striatal circuitry may help in shedding new light on disease-specific pathophysiological mechanisms and even in guiding more targeted pharmacological interventions.

\section{Conclusions}

The present work summarizes the state-of-art knowledge regarding striatal anatomical and functional organization. Anatomical studies in non-human primates make evident two main levels of organization of corticostriatal circuitry: i) the first level of organization, according to subcortical connectivity, differentiates the direct and indirect pathway and is mirrored by differential expression of D1 and D2 dopamine receptors; ii) the second level of organization, based on cortical connectivity, differentiates distinct, segregated yet integrated cortical input-output channels within the basal ganglia circuitry. This latter level of organization has been subject of increasing interest in the human neuroimaging field in the last two decades; above and beyond being repeatedly confirmed by in vivo, non-invasive structural and functional imaging of the human brain, such level of organization has been also recognized as a fundamental underpinning of cortico-striatal integration of information across complex motor and non-motor behavior. Selective, topographically distinct alterations in corticostriatal circuits are thought to underlie different psychiatric and neurologic symptoms of brain diseases. However, further research is still needed to clarify the molecular basis of such relevant level of organization. In the present work, we reviewed the existing literature based on animal models and the recently expanding field of human neurotranscriptomics in search of potential correlates of this level of organization. Recent evidence suggests that corticostriatal topographical organization may be mirrored by multiple molecular levels, including patterns of expression of dopamine and glutamate receptors, and neuropeptides associated both with dopamine neurons and with GABA-ergic interneurons. However, 
we are still far from cracking the molecular code behind corticostriatal topography. In the present work, we underline the relevance of this topic in better understanding genetic and molecular mechanisms behind different brain diseases and the development of novel therapeutic strategies, and we warrant further research towards a complete integration of multimodal imaging, histochemistry and transcriptomics. ${ }^{176}$ In this view, a more comprehensive and detailed knowledge on cortico-striatal functional organization may pave the way towards a better understanding of how the whole cortico-basal ganglia system works in health and disease.

\section{References}

1. DiFiglia M, Carey J. Large neurons in the primate neostriatum examined with the combined Golgi-electron microscopic method. J Comp Neurol 1986;244:36-52.

2. Graveland GA, Difiglia M. The frequency and distribution of medium-sized neurons with indented nuclei in the primate and rodent neostriatum. Brain Res 1985;327:307-11.

3. Pasik P, Pasik T, Holstein GR, Hámori J. GABAergic elements in the neuronal circuits of the monkey neostriatum: a light and electron microscopic immunocytochemical study. J Comp Neurol 1988;270:157-70.

4. Alexander GE, Crutcher MD, DeLong MR. Basal gangliathalamocortical circuits: parallel substrates for motor, oculomotor, 'prefrontal' and 'limbic' functions. Prog Brain Res 1990;85:119-46.

5. Karachi C, Francois C, Parain K, Bardinet E, Tande D, Hirsch $\mathrm{E}$, et al. Three-dimensional cartography of functional territories in the human striatopallidal complex by using calbindin immunoreactivity. J Comp Neurol 2002;450:122-34.

6. Mehlman ML, Winter SS, Taube JS. Functional and anatomical relationships between the medial precentral cortex, dorsal striatum, and head direction cell circuitry. II. Neuroanatomical studies. J Neurophysiol 2019;121:371-95.

7. Flaherty A, Graybiel A. Input-output organization of the sensorimotor striatum in the squirrel monkey. J Neurosci 1994;14:599-610.

8. Fraņois C, Grabli D, McCairn K, Jan C, Karachi C, Hirsch $\mathrm{EC}$, et al. Behavioural disorders induced by external globus pallidus dysfunction in primates II. Anatomical study. Brain 2004; 127:2055-70.

9. Karachi C, Yelnik J, Tandé D, Tremblay L, Hirsch EC, François C. The pallidosubthalamic projection: An anatomical substrate for nonmotor functions of the subthalamic nucleus in primates. Mov Disord 2005;20:172-80.

10. Saga Y, Hoshi E, Tremblay L. Roles of multiple globus pallidus territories of monkeys and humans in motivation, cognition and action: An anatomical, physiological and pathophysiological review. Front Neuroanat 2017;11:30.

11. Cacciola A, Milardi D, Anastasi GP, Basile GA, Ciolli P, Irrera $\mathrm{M}$, et al. A direct cortico-nigral pathway as revealed by constrained spherical deconvolution tractography in humans. Front Hum Neurosci 2016;10:374.

12. Cacciola A, Milardi D, Quartarone A. Role of cortico-pallidal connectivity in the pathophysiology of dystonia. Brain 2016;139:e48.

13. Cacciola A, Milardi D, Anastasi G, Quartarone A. Corticopallidal connectivity: lessons from patients with dystonia. Ann Neurol 2018;84:158.

14. Milardi D, Quartarone A, Bramanti A, Anastasi G, Bertino S, Basile GA, et al. The cortico-basal ganglia-cerebellar network: Past, present and future perspectives. Front Syst Neurosci 2019;13:61.
15. Quartarone A, Cacciola A, Milardi D, Ghilardi MF, Calamuneri A, Chillemi G, et al. New insights into corticobasal-cerebellar connectome: clinical and physiological considerations. Brain 2020;143:396-406.

16. Jarbo K, Verstynen TD. Converging structural and functional connectivity of orbitofrontal, dorsolateral prefrontal, and posterior parietal cortex in the human striatum. J Neurosci 2015;35:3865-78.

17. Haber SN. Corticostriatal circuitry. in: DW Pfaff, Volkow ND, Editors. Neuroscience in the 21st century: From basic to clinical. Cham: Springer; 2016. p. 1721-41.

18. Haber SN. The primate basal ganglia: parallel and integrative networks. J Chem Neuroanat 2003;26:317-30.

19. Gerfen CR, Herkenham M, Thibault J. The neostriatal mosaic: II. Patch- and matrix-directed mesostriatal dopaminergic and non-dopaminergic systems. J Neurosci 1987;7:3915-34.

20. Gerfen CR, Baimbridge KG, Thibault J. The neostriatal mosaic: III. Biochemical and developmental dissociation of patchmatrix mesostriatal systems. J Neurosci 1987;7:3935-44.

21. Brimblecombe KR, Cragg SJ. The Striosome and matrix compartments of the striatum: a path through the labyrinth from neurochemistry toward function. ACS Chem Neurosci 2017;8:235-42.

22. Tremblay L, Worbe Y, Thobois S, Sgambato-Faure V, Féger J. Selective dysfunction of basal ganglia subterritories: From movement to behavioral disorders. Mov Disord 2015;30:1155-70.

23. Haber SN, McFarland NR. The concept of the ventral striatum in nonhuman primates. Ann N Y Acad Sci 1999;877:33-48.

24. Haber SN, Lynd E, Klein C, Groenewegen HJ. Topographic organization of the ventral striatal efferent projections in the rhesus monkey: An anterograde tracing study. J Comp Neurol 1990;293:282-98.

25. Parent A, Bouchard C, Smith Y. The striatopallidal and striatonigral projections: two distinct fiber systems in primate. Brain Res 1984;303:385-90.

26. Levesque M, Parent A. The striatofugal fiber system in primates: A reevaluation of its organization based on single-axon tracing studies. Proc Natl Acad Sci USA 2005;102:11888-93.

27. Smith Y, Parent A. Differential connections of caudate nucleus and putamen in the squirrel monkey (Saimiri sciureus). Neuroscience 1986;18:347-71.

28. Kawaguchi Y, Wilson CJ, Augood SJ, Emson PC. Striatal interneurones: chemical, physiological and morphological characterization. Trends Neurosci 1995;18:527-35.

29. Mesulam M-M, Mash D, Hersh L, Bothwell M, Geula C. Cholinergic innervation of the human striatum, globus pallidus, subthalamic nucleus, substantia nigra, and red nucleus. J Comp Neurol 1992;323:252-68.

30. Tepper JM, Tecuapetla F, Koós T, Ibáñez-Sandoval O. Heterogeneity and diversity of striatal GABAergic interneurons. Front Neuroanat 2010;4:150.

31. Yeterian EH, Van Hoesen GW. Cortico-striate projections in the rhesus monkey: The organization of certain cortico-caudate connections. Brain Res 1978;139:43-63.

32. Selemon L, Goldman-Rakic P. Longitudinal topography and interdigitation of corticostriatal projections in the rhesus monkey. J Neurosci 1985;5:776-94.

33. McFarland NR, Haber SN. Organization of thalamostriatal terminals from the ventral motor nuclei in the macaque. J Comp Neurol 2001;429:321-36.

34. Raju D V., Shah DJ, Wright TM, Hall RA, Smith Y. Differential synaptology of vGluT2-containing thalamostriatal afferents between the patch and matrix compartments in rats. J Comp Neurol 2006;499:231-23. 
35. Haber SN, Fudge JL, McFarland NR. Striatonigrostriatal pathways in primates form an ascending spiral from the shell to the dorsolateral striatum. J Neurosci 2000;20:2369-82.

36. Waselus M, Galvez JP, Valentino RJ, Van Bockstaele EJ. Differential projections of dorsal raphe nucleus neurons to the lateral septum and striatum. J Chem Neuroanat 2006;31:233-42.

37. Haber SN, Knutson B. The reward circuit: Linking primate anatomy and human imaging. Neuropsychopharmacology 2010;35:4-26.

38. Russchen FT, Bakst I, Amaral DG, Price JL. The amygdalostriatal projections in the monkey. An anterograde tracing study. Brain Res 1985;329:241-57.

39. Ding J, Peterson JD, Surmeier DJ. Corticostriatal and thalamostriatal synapses have distinctive properties. J Neurosci 2008;28:6483-92.

40. Lynd-Balta E, Haber SN. The organization of midbrain projections to the striatum in the primate: Sensorimotor-related striatum versus ventral striatum. Neuroscience 1994;59:625-40.

41. Haber SN. The place of dopamine in the cortico-basal ganglia circuit. Neuroscience 2014;282:248-57.

42. Mengod G, Nguyen H, Le H, Waeber C, Lübbert H, Palacios JM. The distribution and cellular localization of the serotonin $1 \mathrm{C}$ receptor mRNA in the rodent brain examined by in situ hybridization histochemistry. Comparison with receptor binding distribution. Neuroscience 1990;35:577-91.

43. Herkenham M, Pert CB. Mosaic distribution of opiate receptors, parafascicular projections and acetylcholinesterase in rat striatum. Nature 1981;291:415-8.

44. Gerfen CR. The neostriatal mosaic. I. compartmental organization of projections from the striatum to the substantia nigra in the rat. J Comp Neurol 1985;236:454-76.

45. Bolam JP, Izzo PN, Graybiel AM. Cellular substrate of the histochemically defined striosome/matrix system of the caudate nucleus: A combined golgi and immunocytochemical study in cat and ferret. Neuroscience 1988;24:853-75.

46. Flaherty AW, Graybiel AM. Input-output organization of the sensorimotor striatum in the squirrel monkey. J Neurosci 1994;14:599-610.

47. Holt DJ, Graybiel AM, Saper CB. Neurochemical architecture of the human striatum. J Comp Neurol 1997;384:1-25.

48. Smith JB, Klug JR, Ross DL, Howard CD, Hollon NG, Ko VI, et al. Genetic-based dissection unveils the inputs and outputs of striatal patch and matrix compartments. Neuron 2016;91:1069-14.

49. Martin LJ, Hadfield MG, Dellovade TL, Price DL. The striatal mosaic in primates: Patterns of neuropeptide immunoreactivity differentiate the ventral striatum from the dorsal striatum. Neuroscience 1991;43:397-417.

50. Meyer G, Gonzalez-Hernandez T, Carrillo-Padilla F, Ferres-Torres R. Aggregations of granule cells in the basal forebrain (islands of Calleja): Golgi and cytoarchitectonic study in different mammals, including man. J Comp Neurol 1989;284:405-28.

51. Fallon JH. The islands of Calleja complex of rat basal forebrain II: Connections of medium and large sized cells. Brain Res Bull 1983;10:775-93.

52. Fallon JH, Loughlin SE, Ribak CE. The islands of Calleja complex of rat basal forebrain. III. Histochemical evidence for a striatopallidal system. J Comp Neurol 1983;218:91-120.

53. Bernier P, Parent A. The anti-apoptosis bcl-2 proto-oncogene is preferentially expressed in limbic structures of the primate brain. Neuroscience 1997;82:635-40.

54. Reiner A, Medina L, Veenman CL. Structural and functional evolution of the basal ganglia in vertebrates. Brain Res Rev 1998;28:235-85.
55. Albin RL, Young AB, Penney JB. The functional anatomy of basal ganglia disorders. Trends Neurosci 1989;12:366-75.

56. DeLong M, Wichmann T. Update on models of basal ganglia function and dysfunction. P Parkinsonism Relat Disord 2009; 15:S237-40.

57. Cui G, Jun SB, Jin X, Pham MD, Vogel SS, Lovinger DM, et al. Concurrent activation of striatal direct and indirect pathways during action initiation. Nature 2013;494:238-42.

58. Klaus A, Martins GJ, Paixao VB, Zhou P, Paninski L, Costa RM. The spatiotemporal organization of the striatum encodes action space. Neuron 2017;95:1171-80.e7.

59. Gerfen C, Engber T, Mahan L, Susel Z, Chase T, Monsma F, et al. D1 and D2 dopamine receptor-regulated gene expression of striatonigral and striatopallidal neurons. Science 1990;250:1429-32.

60. Reiner A, Medina L, Haber S. The distribution of dynorphinergic terminals in striatal target regions in comparison to the distribution of substance P-containing and enkephalinergic terminals in monkeys and humans. Neuroscience 1999;88:775-93.

61. Gokce O, Stanley GM, Treutlein B, Neff NF, Camp JG, Malenka RC, et al. Cellular taxonomy of the mouse striatum as revealed by single-cell RNA-Seq. Cell Rep 2016;16:1126-37.

62. Alexander GE, DeLong MR, Strick PL. Parallel organization of functionally segregated circuits linking basal ganglia and cortex. Annu Rev Neurosci 1986;9:357-81.

63. Kunishio K, Haber SN. Primate cingulostriatal projection: Limbic striatal versus sensorimotor striatal input. J Comp Neurol 1994;350:337-56.

64. Calzavara R, Mailly P, Haber SN. Relationship between the corticostriatal terminals from areas 9 and 46, and those from area $8 \mathrm{~A}$, dorsal and rostral premotor cortex and area $24 \mathrm{c}$ : an anatomical substrate for cognition to action. Eur J Neurosci 2007;26:2005-24.

65. Haber S, Kunishio K, Mizobuchi M, Lynd-Balta E. The orbital and medial prefrontal circuit through the primate basal ganglia. J Neurosci 1995;15:4851-67.

66. Yeterian EH, Pandya DN. Prefrontostriatal connections in relation to cortical architectonic organization in rhesus monkeys. J Comp Neurol 1991;312:43-67.

67. Künzle H. Bilateral projections from precentral motor cortex to the putamen and other parts of the basal ganglia. An autoradiographic study inMacaca fascicularis. Brain Res 1975;88:195-209.

68. Yeterian EH, Pandya DN. Corticostriatal connections of extrastriate visual areas in rhesus monkeys. J Comp Neurol 1995;352:436-57.

69. Yeterian EH, Pandya DN. Striatal connections of the parietal association cortices in rhesus monkeys. J Comp Neurol 1993;332:175-97.

70. Yeterian EH, Pandya DN. Corticostriatal connections of the superior temporal region in rhesus monkeys. J Comp Neurol 1998;399:384-402.

71. Shipp S. The functional logic of corticostriatal connections. Brain Struct Funct 2017;222:669-706.

72. Parent A, Hazrati LN. Functional anatomy of the basal ganglia. Brain Res Rev 1995;20:128-54.

73. Parent A, Hazrati LN. Anatomical aspects of information processing in primate basal ganglia. Trends Neurosci 1993;16:111-6.

74. Hunnicutt BJ, Jongbloets BC, Birdsong WT, Gertz KJ, Zhong $\mathrm{H}$, Mao T. A comprehensive excitatory input map of the striatum reveals novel functional organization. Elife 2016;5:e19103.

75. Donnan GA, Kaczmarczyk SJ, Paxinos G, Chilco PJ, Kalnins 
RM, Woodhouse DG, et al. Distribution of catecholamine uptake sites in human brain as determined by quantitative [3H] mazindol autoradiography. J Comp Neurol 1991;304: 419-34.

76. Kaufman MJ, Madras BK. Distribution of cocaine recognition sites in monkey brain: II. Ex vivo autoradiography with [3H]CFT and [125I]RTI-55. Synapse 1992;12:99-111.

77. Miller GW, Staley JK, Heilman CJ, Ferez JT, Mash DC, Rye $\mathrm{DB}$, et al. Immunochemical analysis of dopamine transporter protein in Parkinson's disease. Ann Neurol 1997;41:530-9.

78. Cragg SJ, Hille CJ, Greenfield SA. Functional domains in dorsal striatum of the nonhuman primate are defined by the dynamic behavior of dopamine. J Neurosci 2002;22:5705-12.

79. Hörtnagl H, Pifl C, Hörtnagl E, Reiner A, Sperk G. Distinct gradients of various neurotransmitter markers in caudate nucleus and putamen of the human brain. J Neurochem 2020;152:650-62.

80. Piggott MA, Marshall EF, Thomas N, Lloyd S, Court JA, Jaros E et al. Dopaminergic activities in the human striatum: Rostrocaudal gradients of uptake sites and of D1 and D2 but not of D3 receptor binding or dopamine. Neuroscience 1999; 90:433-45.

81. Levey AI, Hersch SM, Rye DB, Sunahara RK, Niznik HB, Kitt CA et al. Localization of D1 and D2 dopamine receptors in brain with subtype-specific antibodies. Proc Natl Acad Sci USA 1993;90:8861-5.

82. Joyce JN, Gurevich EV. D3 receptors and the actions of neuroleptics in the ventral striatopallidal system of schizophrenics. Ann N Y Acad Sci 1999;877:595-613.

83. Murray AM, Ryoo HL, Gurevich E, Joyce JN. Localization of dopamine D3 receptors to mesolimbic and D2 receptors to mesostriatal regions of human forebrain. Proc Natl Acad Sci USA 1994;91:11271-5.

84. Gurevich EV, Joyce JN. Distribution of dopamine D3 receptor expressing neurons in the human forebrain comparison with D2 receptor expressing neurons. Neuropsychopharmacology 1999;20:60-80.

85. Bernácer J, Prensa L, Giménez-Amaya JM. Cholinergic interneurons are differentially distributed in the human striatum. PLoS One 2007;2:e1174.

86. Wallman MJ, Gagnon D, Parent M. Serotonin innervation of human basal ganglia. Eur J Neurosci 2011;33:1519-32.

87. Olsen CM, Huang Y, Goodwin S, Ciobanu DC, Lu L, Sutter $\mathrm{TR}$, et al. Microarray analysis reveals distinctive signaling between the bed nucleus of the stria terminalis, nucleus accumbens, and dorsal striatum. Physiol Genomics 2008;32:283-98.

88. Puighermanal E, Castell L, Esteve-Codina A, Melser S, Kaganovsky K, Zussy C, et al. Functional and molecular heterogeneity of D2R neurons along dorsal ventral axis in the striatum. Nat Commun 2020;11:1-15.

89. Märtin A, Calvigioni D, Tzortzi O, Fuzik J, Wärnberg E, Meletis K. A Spatiomolecular Map of the Striatum. Cell Rep 2019;29 4320-33.e5.

90. Basile GA, Bertino S, Bramanti A, Anastasi GP, Milardi D, Cacciola A. In vivo super-resolution track-density imaging for thalamic nuclei identification. Cereb Cortex 2021;bhab184. Online Ahead of Print.

91. Jeurissen B, Descoteaux M, Mori S, Leemans A. Diffusion MRI fiber tractography of the brain. NMR Biomed 2019;32:e3785.

92. Bertino S, Basile GA, Anastasi G, Bramanti A, Fonti B, Cavallaro F, et al. Anatomical characterization of the human structural connectivity between the pedunculopontine nucleus and globus pallidus via multi-shell multi-tissue tractography.
Medicina (Kunas) 2020;56:452.

93. Cacciola A, Bertino S, Basile GA, Di Mauro D, Calamuneri A, Chillemi G, et al. Mapping the structural connectivity between the periaqueductal gray and the cerebellum in humans. Brain Struct Funct 2019;224:2153-65.

94. Cacciola A, Milardi D, Basile GA, Bertino S, Calamuneri A, Chillemi $\mathrm{G}$, et al. The cortico-rubral and cerebello-rubral pathways are topographically organized within the human red nucleus. Sci Rep 2019;9:1-12.

95. Milardi D, Cacciola A, Cutroneo G, Marino S, Irrera M, Cacciola $\mathrm{G}$, et al. Red nucleus connectivity as revealed by constrained spherical deconvolution tractography. Neurosci Lett 2016;626:68-73.

96. Calamuneri A, Arrigo A, Mormina E, Milardi D, Cacciola A, Chillemi G, et al. White matter tissue quantification at low bvalues within constrained spherical deconvolution framework. Front Neurol 2018;9:716.

97. Fox MD, Snyder AZ, Vincent JL, Corbetta M, Van Essen DC, Raichle ME. The human brain is intrinsically organized into dynamic, anticorrelated functional networks. Proc Natl Acad Sci USA 2005;102:9673-8.

98. Basser PJ, Pajevic S, Pierpaoli C, Duda J, Aldroubi A. In vivo fiber tractography using DT-MRI data. Magn Reson Med 2000;44:625-32.

99. Lehéricy S, Ducros M, Van De Moortele PF, Francois C, Thivard L, Poupon C, et al. Diffusion tensor fiber tracking shows distinct corticostriatal circuits in humans. Ann Neurol 2004;55:522-9.

100. Hoshi E, Tremblay L, Féger J, Carras PL, Strick PL. The cerebellum communicates with the basal ganglia. Nat Neurosci 2005;8:1491-3.

101. Leh SE, Ptito A, Chakravarty MM, Strafella AP. Fronto-striatal connections in the human brain: A probabilistic diffusion tractography study. Neurosci Lett 2007;419:113-8.

102. Farquharson S, Tournier J-D, Calamante F, Fabinyi G, Schneider-Kolsky M, Jackson GD, et al. White matter fiber tractography: why we need to move beyond DTI. J Neurosurg 2013;118:1367-77.

103. Cacciola A, Calamuneri A, Milardi D, Mormina E, Chillemi G, Marino S, et al. A connectomic analysis of the human basal ganglia network. Front Neuroanat 2017;11:85.

104. Utter AA, Basso MA. The basal ganglia: An overview of circuits and function. Neurosci Biobehav Rev 2008;32:333-42.

105. Draganski B, Kherif F, Klöppel S, Cook PA, Alexander DC, Parker GJM, et al. Evidence for segregated and integrative connectivity patterns in the human basal ganglia. J Neurosci 2008;28:7143-52.

106. Bertino S, Basile GA, Bramanti A, Anastasi GP, Quartarone A, Milardi D, et al. Spatially coherent and topographically organized pathways of the human globus pallidus. Hum Brain Mapp 2020;41:4641-61.

107. Di Martino A, Scheres A, Margulies DS, Kelly AMC, Uddin LQ, Shehzad Z, et al. Functional connectivity of human striatum: A resting state fMRI study. Cereb Cortex 2008;18:2735-47.

108. Lenglet C, Abosch A, Yacoub E, de Martino F, Sapiro G, Harel N. Comprehensive in vivo mapping of the human basal ganglia and thalamic connectome in individuals using 7T MRI. PLoS One 2012;7:e29153.

109. Thomas Yeo BT, Krienen FM, Sepulcre J, Sabuncu MR, Lashkari D, Hollinshead M, et al. The organization of the human cerebral cortex estimated by intrinsic functional connectivity. J Neurophysiol 2011;106:1125-65.

110. Choi EY, Yeo BTT, Buckner RL. The organization of the human striatum estimated by intrinsic functional connectivity. J Neurophysiol 2012;108:2242-63. 
111. Margulies DS, Ghosh SS, Goulas A, Falkiewicz M, Huntenburg JM, Langs G, et al. Situating the default-mode network along a principal gradient of macroscale cortical organization. Proc Natl Acad Sci USA 2016;113:12574-9.

112. Haak KV, Marquand AF, Beckmann CF. Connectopic mapping with resting-state fMRI. Neuroimage 2018;170:83-94.

113. Marquand AF, Haak KV, Beckmann CF. Functional corticostriatal connection topographies predict goal-directed behaviour in humans. Nat Hum Behav 2017;1:01469.

114. Tian Y, Margulies DS, Breakspear M, Zalesky A. Topographic organization of the human subcortex unveiled with functional connectivity gradients. Nat Neurosci 2020;23:1421-32.

115. Pauli WM, O'Reilly RC, Yarkoni T, Wager TD. Regional specialization within the human striatum for diverse psychological functions. Proc Natl Acad Sci USA 2016;113:1907-12.

116. Lin A, Adolphs R, Rangel A. Social and monetary reward learning engage overlapping neural substrates. Soc Cogn Affect Neurosci 2012;7:274-81.

117. Izuma K, Saito DN, Sadato N. Processing of social and monetary rewards in the human striatum. Neuron 2008;58:284-94.

118. Delgado MR. Motivation-dependent responses in the human caudate nucleus. Cereb Cortex 2004;14:1022-30.

119. Hedden T, Gabrieli JDE. Shared and selective neural correlates of inhibition, facilitation, and shifting processes during executive control. Neuroimage 2010;51:421-31.

120. Gerardin E, Pochon J-B, Poline J-B, Tremblay L, Van de Moortele P-F, Levy R, et al. Distinct striatal regions support movement selection, preparation and execution. Neuroreport 2004; 15:2327-31.

121. Bingel U, Quante M, Knab R, Bromm B, Weiller C, Büchel C. Single trial fMRI reveals significant contralateral bias in responses to laser pain within thalamus and somatosensory cortices. Neuroimage 2003;18:740-8.

122. Zarate JM, Zatorre RJ. Experience-dependent neural substrates involved in vocal pitch regulation during singing. Neuroimage 2008;40:1871-87.

123. Liu X, Eickhoff SB, Hoffstaedter F, Genon S, Caspers S, Reetz K, et al. Joint multi-modal parcellation of the human striatum: Functions and clinical relevance. Neurosci Bull 2020;36:1123-36.

124. Balleine BW. Neural bases of food-seeking: Affect, arousal and reward in corticostriatolimbic circuits. Physiol Behav 2005;86:717-30.

125. Yin HH, Ostlund SB, Knowlton BJ, Balleine BW. The role of the dorsomedial striatum in instrumental conditioning. Eur J Neurosci 2005;22:513-23.

126. Yin HH, Knowlton BJ, Balleine BW. Lesions of dorsolateral striatum preserve outcome expectancy but disrupt habit formation in instrumental learning. Eur J Neurosci 2004;19:181-9.

127. Yin HH, Knowlton BJ. The role of the basal ganglia in habit formation. Nat Rev Neurosci 2006;7:464-76.

128. Balleine BW, Dickinson A. Goal-directed instrumental action: Contingency and incentive learning and their cortical substrates. Neuropharmacology 1998;37:407-19.

129. Corbit LH, Balleine BW. The role of prelimbic cortex in instrumental conditioning. Behav Brain Res 2003;146:145-57.

130. Killcross S, Coutureau E. Coordination of actions and habits in the medial prefrontal cortex of rats. Cereb Cortex 2003;13:400-8.

131. Tanaka SC, Balleine BW, O'Doherty JP. Calculating consequences: Brain systems that encode the causal effects of actions. J Neurosci 2008;28:6750-5.

132. Balleine BW, O’Doherty JP. Human and rodent homologies in action control: Corticostriatal determinants of goal-directed and habitual action. Neuropsychopharmacology 2010;35:48-69.
133. Liljeholm M, Tricomi E, O’Doherty JP, Balleine BW. Neural correlates of instrumental contingency learning: Differential effects of action-reward conjunction and disjunction. J Neurosci 2011;31:2474-80.

134. Tricomi E, Balleine BW, O’Doherty JP. A specific role for posterior dorsolateral striatum in human habit learning. Eur $\mathrm{J}$ Neurosci 2009;29:2225-32.

135. Knowlton BJ, Patterson TK. Habit formation and the striatum. Curr Top Behav Neurosci 2018;37:275-95.

136. Thorn CA, Atallah H, Howe M, Graybiel AM. Differential dynamics of activity changes in dorsolateral and dorsomedial striatal loops during learning. Neuron 2010;66:781-95.

137. Ito H, Takano H, Arakawa R, Takahashi H, Kodaka F, Takahata K, et al. Effects of dopamine D2 receptor partial agonist antipsychotic aripiprazole on dopamine synthesis in human brain measured by PET with L-[ $\beta-11 C]$ DOPA. PLoS One 2012;7:e46488.

138. Ito H, Takano H, Takahashi H, Arakawa R, Miyoshi M, Kodaka F, et al. Effects of the antipsychotic risperidone on dopamine synthesis in human brain measured by positron emission tomography with L-[ -11C]DOPA: A stabilizing effect for dopaminergic neurotransmission? J Neurosci 2009;29:13730-4.

139. Yamamoto Y, Takahata K, Kubota M, Takano H, Takeuchi H, Kimura Y, et al. Differential associations of dopamine synthesis capacity with the dopamine transporter and D2 receptor availability as assessed by PET in the living human brain. Neuroimage 2021;226:117543.

140. Moses WW. Fundamental limits of spatial resolution in PET. Nucl Instruments Methods Phys Res 2011;648:S236-40.

141. Tziortzi AC, Haber SN, Searle GE, Tsoumpas C, Long CJ, Shotbolt $\mathrm{P}$, et al. Connectivity-based functional analysis of dopamine release in the striatum using diffusion-weighted MRI and positron emission tomography. Cereb Cortex 2014.;24;1165-77.

142. Oldham MC, Konopka G, Iwamoto K, Langfelder P, Kato T, Horvath $\mathrm{S}$, et al. Functional organization of the transcriptome in human brain. Nat Neurosci 2008;11:1271-82.

143. Shen EH, Overly CC, Jones AR. The Allen Human Brain Atlas. Comprehensive gene expression mapping of the human brain. Trends Neurosci 2012;35:711-4.

144. Hawrylycz MJ, Lein ES, Guillozet-Bongaarts AL, Shen EH, $\mathrm{Ng}$ L, Miller JA, et al. An anatomically comprehensive atlas of the adult human brain transcriptome. Nature 2012;489:391-9.

145. Arnatkevičiūtè A, Fulcher BD, Fornito A. Uncovering the transcriptional correlates of hub connectivity in neural networks. Front Neural Circuits 2019;13:47.

146. Vértes PE, Rittman T, Whitaker KJ, Romero-Garcia R, Váša F, Kitzbichler MG, et al. Gene transcription profiles associated with inter-modular hubs and connection distance in human functional magnetic resonance imaging networks. Phil Trans R Soc B 2016;371:20150362.

147. Krienen FM, Yeo BTT, Ge T, Buckner RL, Sherwood CC. Transcriptional profiles of supragranular-enriched genes associate with corticocortical network architecture in the human brain. Proc Natl Acad Sci USA 2016;113:E469-78.

148. Wang GZ, Belgard TG, Mao D, Chen L, Berto S, Preuss TM, et al. Correspondence between Resting-State Activity and Brain Gene Expression. Neuron 2015;88:659-66.

149. Parkes L, Fulcher B, Yücel M, Fornito A. An evaluation of the efficacy, reliability, and sensitivity of motion correction strategies for resting-state functional MRI. Neuroimage 2018;171:415-36.

150. Anderson KM, Krienen FM, Choi EY, Reinen JM, Yeo BTT, 
Holmes AJ. Gene expression links functional networks across cortex and striatum. Nat Commun 2018;9:1428.

151.151 Tepper JM, Koós T, Ibanez-Sandoval O, Tecuapetla F, Faust TW, Assous M. Heterogeneity and diversity of striatal GABAergic interneurons: Update 2018. Front Neuroanat 2018;12:91.

152. Anderson KM, Collins MA, Chin R, Ge T, Rosenberg MD, Holmes AJ. Transcriptional and imaging-genetic association of cortical interneurons, brain function, and schizophrenia risk. Nat Commun 2020;11:2889.

153. Lee K, Holley SM, Shobe JL, Chong NC, Cepeda C, Levine MS, et al. Parvalbumin interneurons modulate striatal output and enhance performance during associative learning. Neuron 2017;93:1451-63.e4.

154. Gritton HJ, Howe WM, Romano MF, DiFeliceantonio AG, Kramer MA, Saligrama V, et al. Unique contributions of parvalbumin and cholinergic interneurons in organizing striatal networks during movement. Nat Neurosci 2019;22:586-97.

155. Holly EN, Davatolhagh MF, Choi K, Alabi OO, Vargas Cifuentes L, Fuccillo M V. Striatal low-threshold spiking interneurons regulate goal-directed learning. Neuron 2019;103:92-101.e6.

156. Gazan A, Rial D, Schiffmann SN. Ablation of striatal somatostatin interneurons affects MSN morphology and electrophysiological properties, and increases cocaine-induced hyperlocomotion in mice. Eur J Neurosci 2020;51:1388-402.

157. Subramanian K, Brandenburg C, Orsati F, Soghomonian JJ, Hussman JP, Blatt GJ. Basal ganglia and autism - a translational perspective. Autism Res 2017;10:1751-75.

158. Lüscher C, Robbins TW, Everitt BJ. The transition to compulsion in addiction. Nat Rev Neurosci 2020;21:247-63.

159. Li A, Zalesky A, Yue W, Howes O, Yan H, Liu Y, et al. A neuroimaging biomarker for striatal dysfunction in schizophrenia. Nat Med 2020;26:558-65.

160. Basile GA, Bramanti A, Bertino S, Cutroneo G, Bruno A, Tisano A, et al. Structural connectivity-based parcellation of the dopaminergic midbrain in healthy subjects and schizophrenic patients. Medicina (Kaunas) 2020;56:686.

161. Burguière E, Monteiro P, Mallet L, Feng G, Graybiel AM. Striatal circuits, habits, and implications for obsessive-compulsive disorder. Curr Opin Neurobiol 2015;30:59-65.

162. Crittenden JR, Graybiel AM. Basal ganglia disorders associated with imbalances in the striatal striosome and matrix compartments. Front. Neuroanat 2011;5:59-83.

163. Parkes L, Fulcher BD, Yücel M, Fornito A. Transcriptional signatures of connectomic subregions of the human striatum. Genes Brain Behav 2017;16:647-63.

164. Smoski MJ, Felder J, Bizzell J, Green SR, Ernst M, Lynch TR, et al. fMRI of alterations in reward selection, anticipation, and feedback in major depressive disorder. J Affect Disord
2009;118:69-78.

165. Fineberg NA, Potenza MN, Chamberlain SR, Berlin HA, Menzies L, Bechara A, et al. Probing Compulsive and impulsive behaviors, from animal models to endophenotypes: A narrative review. Neuropsychopharmacology 2010;35:591604.

166. Kaye WH, Fudge JL, Paulus M. New insights into symptoms and neurocircuit function of anorexia nervosa. Nat Rev Neurosci 2009;10:573-84.

167. Oldehinkel M, Beckmann CF, Pruim RHR, van Oort ESB, Franke B, Hartman CA, et al. Attention-deficit/hyperactivity disorder symptoms coincide with altered striatal connectivity. Biol Psychiatry Cogn Neurosci Neuroimaging 2016;1:353-63.

168. Nieuwhof F, Bloem BR, Reelick MF, Aarts E, Maidan I, Mirelman A, et al. Impaired dual tasking in Parkinson's disease is associated with reduced focusing of cortico-striatal activity. Brain 2017;140:1384-98.

169. Chung SJ, Yoo HS, Oh JS, Kim JS, Ye BS, Sohn YH, et al. Effect of striatal dopamine depletion on cognition in de novo Parkinson's disease. Parkinsonism Relat Disord 2018;51:43-8.

170. Yoo S-W, Oh Y-S, Hwang E-J, Ryu D-W, Lee K-S, Lyoo CH, et al. "Depressed" caudate and ventral striatum dopamine transporter availability in de novo depressed Parkinson's disease. Neurobiol Dis 2019;132:104563.

171. McCutcheon RA, Jauhar S, Pepper F, Nour MM, Rogdaki M, Veronese $\mathrm{M}$, et al. The topography of striatal dopamine and symptoms in psychosis: An Integrative positron emission tomography and magnetic resonance imaging study. Biol Psychiatry Cogn Neurosci Neuroimaging 2020;5:1040-51.

172. McCutcheon RA, Abi-Dargham A, Howes OD. Schizophrenia, dopamine and the striatum: From biology to symptoms. Trends Neurosci 2019;42:205-20.

173. Harrison BJ, Pujol J, Cardoner N, Deus J, Alonso P, LópezSolà $\mathrm{M}$, et al. Brain corticostriatal systems and the major clinical symptom dimensions of obsessive-compulsive disorder. Biol Psychiatry 2013;73:321-8.

174. Tyagi H, Apergis-Schoute AM, Akram H, Foltynie T, Limousin P, Drummond LM, et al. A randomized trial directly comparing ventral capsule and anteromedial subthalamic nucleus stimulation in obsessive-compulsive disorder: Clinical and imaging evidence for dissociable effects. Biol Psychiatry 2019;85 726-34.

175. Barcia JA, Avecillas-Chasín JM, Nombela C, Arza R, GarcíaAlbea J, Pineda-Pardo JA et al. Personalized striatal targets for deep brain stimulation in obsessive-compulsive disorder. Brain Stimul 2019;12:724-34.

176. Basile GA, Quartu M, Bertino S, Serra MP, Boi M, Bramanti A, et al. Red nucleus structure and function: from anatomy to clinical neurosciences. Brain Struct Funct 2021;226:69-91.

Received for publication: 31 May 2021. Accepted for publication: 7 September 2021.

This work is licensed under a Creative Commons Attribution-NonCommercial 4.0 International License (CC BY-NC 4.0).

CCopyright: the Author(s), 2021

Licensee PAGEPress, Italy

European Journal of Histochemistry 2021; 65(s1):3284

doi:10.4081/ejh.2021.3284 